\title{
ИЕРАРХИЧЕСКАЯ СТРУКТУРА ЦЕПОЧЕК СТОИМОСТИ: СТАТИСТИЧЕСКИЙ АНАЛИЗ ПО ДАННЫМ МЕЖРЕГИОНАЛЬНЫХ ТАБЛИЦ «АТРАТЫ-ВЫПУСК»
}

\author{
А.А. Быков, В.А. Пархименко, А.М. Седун**
}

Проведен анализ долгосрочных тенденций и закономерностей, связанных с процессами международной производственной кооперации в рамках глобальных цепочек стоимости, для определения перспектив белорусской экономики в глобальной и региональной системах разделения труда и формирования для нее рекомендаций стратегического порядка. Методология исследования - статистический анализ «Затраты - Выпуск» и иные методы количественного анализа данных с использованием языка R. Информационной базой выступили аналитические отчеты международных организаций и консалтинговых компаний, а также данные межрегиональных таблиц WIOD и Eora.

Ключевые слова: межрегиональные таблицы «Затраты-Выпуск»; национальные, региональные и глобальные цепочки стоимости; макроэкономические показатели; Eora; WIOD.

JEL-классификация: C10, C67, D57, F63, O10.

DOI: $10.46782 / 1818-4510-2021-1-45-58$

Материал поступил 23.02.2021 2.

В феврале 2021 г. в Республике Беларусь были определены новые приоритеты международной экономической политики. Страна и дальше будет придерживаться многовекторной внешней политики, однако приоритетным направлением в экономическом взаимодействии станет Евразийский экономический союз. Если раньше, исходя из требований экономической безопасности, географическая структура белорусского экспорта определялась равно пропорциональной долей трех групп основных торговых партнеров - России, Европейского союза и остальных стран, то теперь на рынок ЕАЭС планируется поставлять до половины белорусского экспорта.

С точки зрения экономической науки и практики, актуальна проблема интенсивности внутрирегионального и межрегионального экономического взаимодействия без привязки к политическим факторам и специфике белорусской экономики, ориентируясь исключительно на долгосрочные экономические тенденции и закономерности, характерные для различных стран и регионов мира. В данном контексте следует рассмотреть следующие вопросы: какими показателями лучше измерять интенсивность экономического взаимодействия стран? Подходят ли в целом показатели экспорта и импорта для этого? Является ли усиление внутрирегионального экономического взаимодействия стран общемировой тенденцией? Если да, тогда текущие изменения во внешнеэкономической политике Беларуси следует рассматривать как исторически обусловленные и закономерные, если нет - как временные и политически ангажированные.

Объектом настоящего исследования выбраны не страны, регионы и отрасли экономики, а глобальные цепочки стоимости,

\footnotetext{
* Работа выполнена при финансовой поддержке БРФФИ.

** Быков Алексей Александрович (aliaksei.bykau@yandex.ru), доктор экономических наук, профессор, Белорусский государственный экономический университет (г. Минск, Беларусь);

Пархименко Владимир Анатольевич (parkhimenko@bsuir.by), кандидат экономических наук, доцент, Белорусский государственный университет информатики и радиоэлектроники (г. Минск, Беларусь);

Седун Андрей Максимович (sedun@bseu.by), кандидат технических наук, профессор, Белорусский государственный экономический университет (г. Минск, Беларусь).
} 
в рамках которых осуществляется производственная кооперация как внутри стран, регионов и отраслей, так и между ними. Информационная база исследования представлена как аналитическими отчетами международных организаций и консалтинговых компаний, так и цифровой информацией, обобщенной в межрегиональных таблицах «Затраты - Выпуск», которые в мировой практике используются для количественного описания глобальных цепочек стоимости.

\section{Обзор литературь}

Довольно часто в научных публикациях процессы глобализации и регионализации рассматриваются как противоположные друг другу явления, при этом замыкание экономики и социума в своем географическом регионе считается способом сохранения собственной культурной идентичности, поддержания конкурентоспособности и обеспечения национальной безопасности в эпоху глобализма. Если глобализация влечет за собой смену технологий, финансовую нестабильность и культурную унификацию на основе общих ценностей, то в качестве «лекарства» от нежелательных изменений предлагается изоляционизм в рамках традиционного социокультурного и технологического укладов с региональной экономической автономией. Альтернативу сложившейся мирохозяйственной модели многие исследователи видят в формировании самодостаточных региональных экономических систем. Этот аспект отметил М.А. Румянцев (2014) в контексте критики идеологии постмодерна в целом и экономической глобализации в частности. Глобализации противопоставляются не только экономически самодостаточные регионы, но и национальные государства: поскольку сторонники глобализма стремятся ослабить национальные государства и выстроить систему наднациональных рыночных регуляторов, постольку усиление роли государства и национальных регуляторов рассматривается как защитная мера со стороны национальных экономик (Рязанов, 2012). Широко известна также иная точка зрения. Сегодня глобализация и региона- лизация становятся взаимно обусловливающими друг друга процессами. Более того, регионализацию все чаще рассматривают как часть глобальных процессов - отмечают М. Лагутина и Е. Михайленко (2020) в обзоре зарубежных подходов к регионализму.

Комплексные вопросы соотношения глобальных, региональных и национальных составляющих в мировой экономической интеграции должны исследоваться в привязке к различным аспектам экономического взаимодействия, включая производственное, финансовое, социокультурное. По нашему мнению, для изучения географической направленности и интенсивности взаимодействия экономик мира в нефинансовом секторе, осуществляющем производство товаров и услуг, нужно рассматривать сам процесс глобализации в более узком смысле, в данном случае как международную производственную кооперацию в рамках глобальных цепочек стоимости (ГЦС). Это позволит избежать анализа сложных геополитических проблем, сконцентрировавшись в большей степени на изучении бизнес-стратегий фирм, а также использовать объективные статистические данные.

Считается, что после кризиса 2008 г. ключевыми и наиболее жизнеспособными субъектами мировой экономики стали связанные группы компаний, названные глобальными производственными сетями, глобальными цепями поставок либо глобальными цепочками стоимости. Взаимодействия фирм в рамках подобных сетевых структур отличаются разнообразием и могут включать как единовременные трансакции через мировые товарные рынки, так и долгосрочные отношения, подкрепленные взаимным участием в капитале, схемами аутсорсинга, общими компьютерными информационными системами. Через локализацию отдельных технологических операций в рамках территориально распределенных процессов производства и поставки конечной продукции ГЦС определяют отраслевую специализацию многих экономик мира. В частности, промышленное развитие Китая и ряда стран Центральной и Восточной Европы было обусловлено прямыми инвестициями из США и Европы, от- 
крытием американского и европейского рынков для производимых товаров.

В качестве иллюстрации фрагментированного (распределенного в пространстве) производства на основе ГЦС приводят структуру себестоимости продуктов компании Apple. Например, в структуре себестоимости собранного в Китае iPod 70\% занимает стоимость японских, корейских и американских компонентов, вклад китайских предприятий не превышает 10\% (Волгина, 2020). Может сложиться впечатление, что все мировое производство построено наподобие бизнеса Apple, однако анализ статистики показывает иное.

Ранее мы провели анализ внешней торговли крупнейших экономик мира на основе показателей добавленной стоимости в экспорте, что позволило выявить специализацию крупнейших стран в глобальной экономике (Быков, Седун, 2015). Например, США и Великобритания поставляют на мировой рынок наукоемкие услуги; Япония, Германия и Корея - высокотехнологичные компоненты продукции; Китай осуществляет сборку конечных продуктов для мирового рынка; Россия и Бразилия поставляют сырье и продукты его переработки. Предложенное схематическое описание мировой экономики через региональную специализацию и кооперацию ключевых участников, дифференцированную по технологическому уровню товаров и услуг, представляло собой обобщенное видение глобальных цепочек стоимости на тот момент, когда тема ГЦС только набирала популярность.

С тех пор прошло пять лет, и детальному рассмотрению глобальных цепочек стоимости посвящено множество научных публикаций. Получил распространение мощный аналитический инструментарий, с помощью которого осуществляется статистический анализ ГЦС - межрегиональные таблицы «Затраты - Выпуск» (Multi-regional Input-Output - MRIO). Работа с MRIO позволяет рассматривать ГЦС не гипотетически, а точно выделять их фрагменты на основе интенсивности взаимодействия экономик мира в разрезе отдельных отраслей или видов экономической деятельности. На основе показателей отечественной и иностранной добавленной стоимости в экспорте, отечественного и импор- тного промежуточного потребления таблицы «Затраты - Выпуск» дают возможность среди всех внешнеторговых операций выделять ту их часть, которая описывает производственную кооперацию между фирмами, а не поставку готовых товаров на отечественный или зарубежные рынки. Кроме того, все поставки товаров и услуг в рамках производственной кооперации можно классифицировать по отраслевому и географическому признакам.

Результаты использования MRIO в исследованиях ГЦС обобщены в отчетах международных организаций, таких как Всемирный банк, ВТО, ОЭСР, а также известных консалтинговых компаний - McKinsey, Ernst\&Young и др. В частности, в Отчете о развитии глобальных цепочек стоимости за 2017 г. ${ }^{1}$ констатируется замедление бурного роста ГЦС, характерного для периода до 2008 г., а также некоторое упрощение ГЦС, которое проявляется в сокращении числа сложных межрегиональных цепочек и росте менее разветвленных региональных цепочек. При этом структура ГЦС иерархична: образовались три региональных центра - интегратора ГЦС (США, Германия и Китай), которые взаимодействуют и объединяют цепочки стоимости более низкого уровня иерархии, преимущественно в своем регионе (рис. 1).

Подробные количественные исследования ГЦС заставляют пересмотреть взгляд на современную экономику как на «мировую фабрику», в которой узкоспециализированные крупные предприятия поставляют продукцию на мировой рынок. Оказалось, в ней достаточно много пространства и для менее крупных производств регионального и национального масштаба. Профессор швейцарского Института международных исследований и развития Ричард Болдуин, известный специалист по международной торговле и теории глобализации, утверждает: термин «глобальные цепочки стоимости» не описывает то, что мы видим сегодня в мировой экономике, потому что мировая экономика не глобальна; она остается регионально изолированной ${ }^{2}$.

1 URL: https://www.worldbank.org/en/topic/trade/ publication/global-value-chain-development-report-measuringand-analyzing-the-impact-of-gvcs-on-economic-development 2 Там же. 


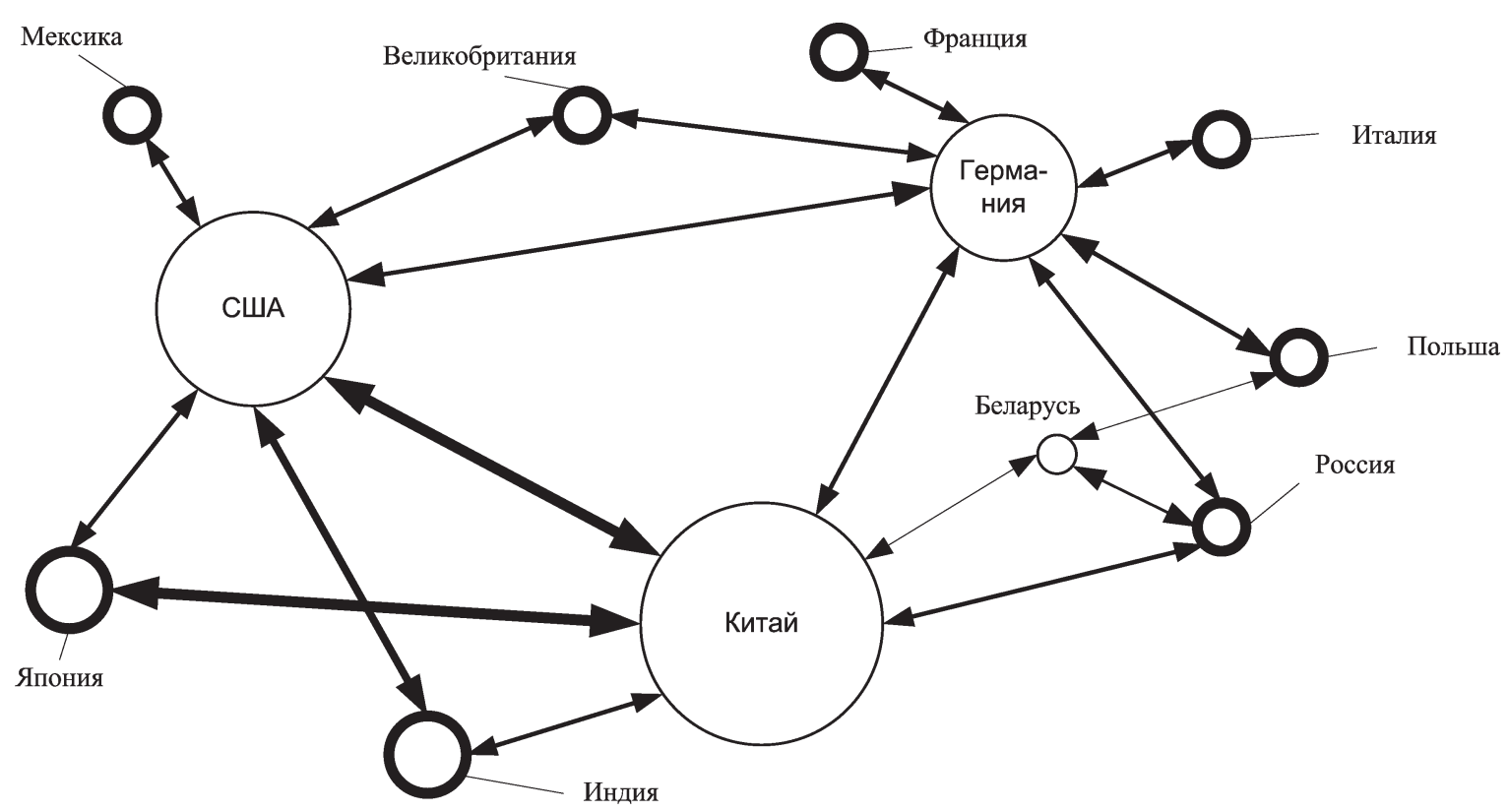

Рис. 1. Взаимосвязанные производственные центры в мировой экономике

Примечание. Размер круга определяется объемом производства, ширина линии - интенсивностью торговли.

Источник. Global Value Chain Development Report: Measuring and Analyzing the Impact of GVCs on Economic Development. 2017. URL: https://www.worldbank.org/en/topic/trade/publication/global-value-chain-development-reportmeasuring-and-analyzing-the-impact-of-gvcs-on-economic-development

В работах (Boys, Andreoni, 2020; Keijser, Belderbos, Goedhuys, 2021) выделяют три уровня иерархии цепочек стоимости: глобальные (ГЦС), региональные (РЦС), а также национальные или локальные (НЦС или ЛЦС). Фирмы развивающихся стран обычно не интегрируются напрямую в ГЦС, а взаимодействуют с глобальными цепочками опосредованно через внутрирегиональную производственную кооперацию.

В отчете «Глобализация в переходный период: будущее торговли и цепочек стоимости» (Lund, Manyika, Woetzel, Bughin, Krishnan, Seong, Muir, 2019) выделяются 5 структурных сдвигов, наблюдаемых в глобальных цепочках стоимости в последние годы. Один из таких сдвигов, по мнению экспертов, заключается в том, что цепочки стоимости становятся в большей степени региональными и в меньшей - глобальными. Так, начиная с 2013 г. доля региональной торговли в общем объеме глобальной торговли выросла на 2,7 п. п. Особенно заметна эта тенденция в Азии (прежде всего, Китае) и 28 странах ЕС (с географической точки зрения), а также в инновационных секторах различных экономик мира.
Изучая причины глобального замедления внешней торговли после кризиса 2008 г., исследователи (Timmer, Los, Stehrer, de Vries, 2016) рассчитали показатель глобальной импортоемкости, используя данные межрегиональных таблиц «Затраты - Выпуск». В работе вводится понятие глобальной импортоемкости (import intensity of world GDP). Констатируется ее снижение, что объясняется двумя возможными причинами:

изменением структуры конечного спроса, когда после мирового кризиса 2008 г. глобальный спрос на товары длительного пользования упал, а спрос на услуги, которые обладают сравнительно меньшей импортоемкостью, вырос;

возможным сокращением глобальных цепочек стоимости.

Существенным фактором, влияющим на интенсивность производственной кооперации, может оказаться расстояние между производителями компонентов, производителями готовых продуктов и их потребителями. В исследованиях данного фактора используют гравитационные модели, применение которых могло бы обосновать пропорции между национальными, региональными и глобаль- 
ными фрагментами цепочек стоимости. В частности, гравитационная модель показала значимые факторы, определяющие интенсивность внешнеторговых операций между странами СНГ, - это размер ВВП, расстояние, наличие общей границы, участие в экономических группировках (Янчук, 2007). В результате исследований международной торговли с 1970 по 2006 г. с помощью гравитационных моделей выявлена закономерность, получившая название «парадокс расстояния» (distance puzzle) - см., например, (Brun, Carrure, Guillaumont, de Melo, 2005). Фактор расстояния оказывает все меньшее влияние на экономическое взаимодействие крупнейших развитых экономик, в отличие от торговых, технических барьеров и прочих институциональных факторов. Однако, если рассматривать развивающиеся страны, влияние расстояния на интенсивность торговли и производственной кооперации между ними только усиливается (Carrure, de Melo, 2009). В результате ГЦС увеличивают свое присутствие в развитых странах, а в развивающихся распространяются региональные и национальные цепочки стоимости.

Анализируя прямые иностранные инвестиции (ПИИ) в европейские страны в 2014-2015 гг., специалисты Ernst\&Young приходят к выводу, что около половины всех созданных в Европе благодаря притоку ПИИ рабочих мест приходится на экономики Центральной и Восточной Европы (ЦВЕ). При этом 69\% организованных в регионе ЦВЕ проектов было связано с производством, а основными инвесторами выступили европейские компании ${ }^{3}$. Западноевропейские инвесторы создают региональные цепочки стоимости в пределах Европейского союза, как в Западной, так и в Центральной и Восточной Европе. По такому пути пошли Volkswagen, Bosch, Airbus и др.

Глобализация в широком смысле влияет на развитие ГЦС по-разному, то ускоряя, то замедляя мировую промышленную интеграцию. Если первым шоком, замедлившим развитие ГЦС, был мировой финансовый кризис 2008 г., то вторым не менее важным событием мирового масштаба ста-

${ }^{3}$ Исследование инвестиционной привлекательности стран Европы. 2016. Ernst \& Young. 12 р. ла пандемия коронавируса и последовавший локдаун. Анализируя последствия пандемии для ГЦС, К. Шваб и Т. Малльре утверждают, что ГЦС создавались в соответствии с принципом just-in-time - «точно вовремя», т. е. путем минимизации полных затрат на производство и поставку конечного продукта в территориально распределенной сети предприятий, каждое из которых располагалось в регионах с наиболее дешевыми ресурсами. Созданные таким образом глобальные цепочки стоимости оказались чрезвычайно эффективными, но довольно хрупкими, не приспособленными к возможным перебоям в поставках, обусловленными возросшей неопределенностью. Теперь основным условием функционирования ГЦС становится их надежность (resilience), а принципом построения - justin-case («на всякий случай»). Данный принцип на практике означает поддержание избыточных запасов, диверсификацию поставщиков, общее сокращение «длины» цепей поставок с ориентиром на географическое приближение производства деталей и узлов к производству и распределению конечной продукции. Его реализация приведет к росту затрат в таких отраслях, как автомобилестроение, производство электроники, машин и оборудования (Schwab, Malleret, 2020. C.136).

Приведенные экспертные мнения позволяют заключить, по крайней мере, что нет оснований полагать, что дальнейшее углубление отраслевой специализации в экономиках мира будет нарастать, а производственно-сбытовые цепочки усложняться. Скорее, наоборот, происходит упрощение цепочек с географическим приближением производителей к потребителям продукции.

Важно на основе статистических данных оценить в динамике пропорцию: какова доля в мировой экономике в целом и по отдельным видам деятельности глобальных, региональных и национальных фрагментов цепочек стоимости.

\section{Методология: MRIO WIOD и Eora}

Межрегиональная таблица «Затраты Выпуск» (Multi-regional Input-Output table, 
MRIO) - это таблица, построенная по стандартной методологии «Затраты - Выпуск», однако в ней учитывается информация не только по отраслям, но и в территориальном разрезе - по нескольким регионам. Она состоит из трех квадрантов (промежуточное потребление, конечное потребление и добавленная стоимость) и может быть описана системой линейных уравнений, их решение хорошо представлено в литературе.

О межрегиональных таблицах писал еще создатель методологии «Затраты Выпуск» В.В. Леонтьев (Leontief, Strout, 1963). Он же опубликовал работу, в которой предложил описать мировую экономику средствами указанной методологии, выделив всего два региона - развитые и развивающиеся страны (Leontief, 1977). В случае проектов WIOD и Eora речь идет именно о такой модели «Затраты - Выпуск» для всей мировой экономики как единого целого, регионами в данном случае выступают отдельные страны.

Упрощенно межрегиональная таблица «Затраты - Выпуск» представлена на рис. 2.

База WIOD содержит информацию о 43 странах (28 стран ЕС и 15 крупных экономик мира), а также о 44-й квази-стране под названием «Весь остальной мир» (rest of the world). По каждому государству имеются данные по 56 секторам экономики. Помимо традиционных трех квадрантов таблицы «Затраты - Выпуск», WIOD вклю- чает 16 социоэкономических показателей (Socio Economic Accounts) и 5 показателей экологического характера (Environmental Accounts). Последний выпуск WIOD - ноябрь 2016 г. Полные таблицы «Затраты Выпуск» представлены и свободно доступны для скачивания за 2000-2014 гг. Официальный сайт проекта WIOD - wiod.org, а подробное описание методологии можно прочитать в работе (Timmer, Dietzenbacher, Los, Stehrer, de Vries, 2015).

Данные Eora являются более детализированными, так как охватывают 190 стран, однако используемая классификация секторов экономики более узкая - 26 секторов для версии Eora26. Что касается дополнительных показателей, то в Eora coдержится 2720 экологических и социоэкономических показателей. Eora в отличие от WIOD охватывает и более длительный период: данные представлены за 1990-2015 гг. (в том числе учтена информация по СССР). При этом доступны как страновые данные (Individual country IO tables), так и полная версия (Full Eora) и ее упрощенный вариант - Eora26. Официальный сайт проекта worldmrio.com, а описание представлено в работе (Lenzen, Kanemoto, Moran, Geschke, 2012, 2013).

В качестве основных задач, которые можно решать на основе данных WIOD и Eora, стоит упомянуть прогнозирование выпуска в рамках мировой экономики (по отдельной

\begin{tabular}{|c|c|c|c|c|c|}
\hline & & \multicolumn{2}{|c|}{ Промежуточное потребление } & \multicolumn{2}{|c|}{ Конечное использование } \\
\hline & & Страна А & Страна Б & Страна A & Страна Б \\
\hline & & Продукт & Продукт & Продукт & Продукт \\
\hline Страна А & Продукт & $\begin{array}{c}\text { Промежуточное } \\
\text { потребление } \\
\text { отечественного } \\
\text { продукта } \\
\end{array}$ & $\begin{array}{c}\text { Промежуточное } \\
\text { потребление страной Б } \\
\text { экспорта из страны А }\end{array}$ & $\begin{array}{l}\text { Конечное использование } \\
\text { отечественного продукта }\end{array}$ & $\begin{array}{c}\text { Конечное } \\
\text { использование } \\
\text { страной Б экспорта } \\
\text { из страны А } \\
\end{array}$ \\
\hline Страна Б & Продукт & $\begin{array}{c}\text { Промежуточное } \\
\text { потребление страной } \\
\text { А экспорта из страны } \\
\text { Б } \\
\end{array}$ & $\begin{array}{c}\text { Промежуточное } \\
\text { потребление } \\
\text { отечественного } \\
\text { продукта } \\
\end{array}$ & $\begin{array}{c}\text { Конечное использование } \\
\text { страной А экспорта из } \\
\text { страны Б }\end{array}$ & $\begin{array}{c}\text { Конечное } \\
\text { использование } \\
\text { отечественного } \\
\text { продукта } \\
\end{array}$ \\
\hline \multicolumn{2}{|c|}{$\begin{array}{l}\text { Добавленная } \\
\text { стоимость }\end{array}$} & ДС(А) & ДС(Б) & & \\
\hline \multicolumn{2}{|c|}{ Валовой выпуск } & $\mathrm{BB}(\mathrm{A})$ & $\mathrm{BB}(\mathrm{Б})$ & & \\
\hline
\end{tabular}

Рис. 2. Структура межрегиональной таблицы «Затраты - Выпуск»

Источник. Global value chains and development: Investment and value added trade in the global economy. 2013. UNCTAD. URL: https://unctad.org/system/files/official-document/diae2013d1_en.pdf 
стране или сектору), оценку устойчивости технологических коэффициентов на протяжении последних десятилетий, оценку экологической нагрузки (environmental footprints) по, например, выбросам $\mathrm{CO}_{2}$, оценку социальных последствий - например, изменения уровня занятости, анализ глобальных цепочек стоимости, изучение одной конкретной отрасли в рамках глобальной экономики (Пархименко, 2020) или прогнозирование влияния COVID-19 на валовой выпуск и ВBП.

Отметим, что работа с данными WIOD и Eora сопряжена с рядом сложностей. Далеко не по всем странам есть полная и качественная статистика. Это хотя и не мешает работать с общей моделью глобальной экономики, так как основные страны представлены хорошо, все же не позволяет проводить глубокий анализ отдельных деталей общей картины. Известно также, что официальные данные разных стран по взаимному импорту-экспорту противоречат друг другу, поэтомy WIOD и Eora отражают некоторые «компромиссные» решения. Кроме того, в представленных данных есть опечатки и некорректные значения (например, нулевые или даже отрицательные величины). Несбалансированность таблицы (Eora), ее искусственная балансировка (WIOD) - еще одна проблема. Наконец, как указывалось ранее, последние актуальные данные относятся к 2014-2015 гг.

Движение товаров и услуг между странами и регионами мира, а также между секторами внутри национальных экономик в рамках цепочек стоимости составляет лишь ту часть общих торговых потоков, которая связана с производственной кооперацией между фирмами. В Системе национальных счетов товары и услуги, производимые одними фирмами для использования другими фирмами, называются промежуточными продуктами. Именно промежуточные продукты иллюстрируют в совокупности все коопера- ционные связи, возникающие в рамках производства и доведения до потребителя конечного продукта, который по структуре своих затрат может оказаться глобальным, региональным или национальным, в зависимости от региона происхождения этих затрат.

Общие промежуточные затраты по каждому продукту, всем продуктам в рамках национальной экономики или региона складываются из национальной, региональной и глобальной составляющих промежуточных затрат:

$$
\Pi \Pi_{\text {общ }}=\Pi \Pi_{\text {нац }}+\Pi \Pi_{\text {рег }}+\Pi \Pi_{\text {глоб. }}
$$

Особый интерес представляют относительные доли указанных составляющих в общей сумме промежуточных затрат:

$$
\frac{\Pi_{\text {нац }}}{\Pi \Pi_{\text {общ }}}+\frac{\Pi_{\text {рег }}}{\Pi_{\text {общ }}}+\frac{\Pi \Pi_{\text {глоб }}}{\Pi \Pi_{\text {общ }}}=1 .
$$

Эти показатели (табл. 1) указывают на доминирующий уровень производственной интеграции в данной отрасли или по всей экономике, или региону.

Если рассматривать динамику основных показателей MRIO, важное значение также имеет изменение доли национальной экономики или региона в общемировом валовом выпуске, что свидетельствует о структурных изменениях в глобальном производстве. Общепринятым оценочным показателем отрасли или экономики является, соответственно, ВДС или ВВП, однако широкое распространение аутсорсинга привело к дроблению бизнесов и отраслей, вынесению вспомогательных и даже основных видов деятельности за пределы фирмы. В этом смысле выпуск отражает «сборку» конечного продукта из промежуточных продуктов, страну происхождения которых легко определить и выделить национальную и импортную доли.

Таблица 1

Логика конструирования показателей национальной, региональной и глобальной состав ляющих промежуточных затрат

\begin{tabular}{|l|c|}
\hline \multicolumn{1}{|c|}{ Потоки промежуточных товаров и услуг } & Промежуточное потребление в стране $i$ \\
\hline Из страны $i$ & $\Pi_{\text {нац }}$ \\
\hline Из стран региона $j$ (за исключением страны $i$ ) & $\Pi_{\text {рег }}$ \\
\hline Из всех стран, не входящих в регион $j$ & $\Pi_{\text {глоб }}$ \\
\hline Итого & $\Pi_{\text {обш }}$ \\
\hline
\end{tabular}

Источник. Авторская разработка. 
Общепринятой в MRIO стала оценка международной торговли в показателях добавленной стоимости, основным оценочным показателем является добавленная стоимость национального происхождения в экспорте. На основе его оценки с применением отраслевых показателей импортоемкости определяется вклад экспорта и внутреннего спроса в ВВП, а валовой продукт делится на части - часть ВВП, созданная за счет экспорта товаров и услуг (GVA attributed to exports), a также часть ВВП, созданная за счет конечного спроса в национальной экономике (GVA attributed to final demand $)^{4}$. Если суммировать первый из названных показателей по всем странам и отнести полученную величину к общемировой ВДС, получится вклад глобального экспорта в ВВП. Увеличение этого показателя будет свидетельствовать о росте открытости и преобладании тенденций интеграции в мировой экономике, обратная тенденция - о росте влияния внутренних и региональных рынков на экономический рост.

Подготовка данных MRIO WIOD и Eora для дальнейшего использования включает выделение анализируемых показателей в разрезе рассматриваемых отраслей и регионов.

Мы взяли четыре региона мировой экономики, ориентируясь, главным образом, на наличие устойчивых кооперационных связей внутри регионов, наличие информации по регионам в базах WIOD и Eora, а также сопоставимость регионов по размеру экономики (табл. 2). Выделить регион ЕАЭС или СНГ

${ }^{4}$ Economic Indicators for Eastern Asia. Input-Output Tables. December 2018. Asian Development Bank. URL: https:// www.adb.org/publications/economic-indicators-eastern-asia-inputoutput-tables оказалось невозможным, поскольку в WIOD из всех стран региона представлена только Россия, а в Eora данные по этим странам некорректны: показатели по Армении и Казахстану сильно завышены, по Беларуси и Молдове занижены. Кроме того, регион СНГ несопоставим по размеру экономики с другими, более крупными экономическими регионами мира.

Eora глубоко детализирована по странам, а в отраслевом разрезе глубже детализирована WIOD, в которой выделяется 56 секторов против 26 в Еora. Нами проанализированы показатели выпуска и промежуточного потребления как в целом по экономикам, так и в разрезе отраслей (продуктов) обрабатывающей промышленности, которые в наибольшей степени ориентированы на участие в ГЦС ввиду широкого распространения в этих отраслях промышленной кооперации на основе аутсорсинга. Кроме того, выбранные для анализа отрасли промышленности отличаются высокой наукоемкостью, в себестоимости выпускаемых ими продуктов высока доля затрат на научные исследования и разработки, информационные технологии, прочие бизнесуслуги (около 14\% к общему промежуточному потреблению у европейских и американских производителей).

К анализируемым отраслям промышленности в WIOD мы отнесли 6 отраслей: C21: производство основных фармацевтических продуктов и фармацевтических препаратов; С26-С30: производство компьютерной, электронной и оптической продукции; производство электрооборудования; производство машин и оборудования; производство автомобилей, прицепов и полу-

Таблица 2

Регионы мира, выбранные для анализа, по составу стран

\begin{tabular}{|c|c|c|}
\hline Регион & WIOD & Еога \\
\hline Европа & $\begin{array}{c}\text { 28 стран Европейского союза, включая } \\
\text { Великобританию, плюс Норвегия и } \\
\text { Швейцария }\end{array}$ & США, Канада \\
\hline Северная Америка & США, Канада & жаная \\
\hline Азия & $\begin{array}{c}\text { Австралия, Индия, Индонезия, Китай, } \\
\text { Тайвань, Турция, Ю. Корея, Япония }\end{array}$ & $\begin{array}{c}\text { Все страны географической Азии, } \\
\text { включая Турцию, за исключением } \\
\text { стран СНГ }\end{array}$ \\
\hline Остальной мир & Не указанные выше страны & Не указанные выше страны \\
\hline
\end{tabular}

Источник. Авторская разработка. 
прицепов; производство прочего транспортного оборудования. В базе Eora26 данным группам отраслей соответствуют лишь две: электротехника и оборудование; транспортное оборудование. Далее выбранные для анализа отрасли будем условно называть наукоемкими отраслями промышленности.

\section{Основные результаты анализа}

Динамика объема выпуска. Структура общего объема выпуска мировой экономики (данные WIOD, с 2000 по 2014 г.), разделенного на четыре региона, такова: доля Северной Америки в общемировом выпуске снизилась с 32 до 21\%; доля Европы снизилась с 27 до 23\%; доля Азии выросла с 25 до 34\%; доля остального мира выросла с 14 до 22\%. Более детальный анализ выпуска наукоемких отраслей промышленности по данным Eora за период с 1990 по 2015 г. показывает схожую динамику (рис. 3).

По выпуску наукоемких промышленных продуктов азиатские страны еще в большей степени опережают европейских и американских производителей. Переломным стал период с 2007 по 2010 г., на который пришелся мировой финансовый кризис. Как следствие, суммарная доля ЕС и США в валовом выпуске продукции наукоемкой промышленности снизилась на 12 п. п.

Вклад экспорта в экономический рост. В этот же период произошел разворот тренда в мировой торговле. Рост влияния международной торговли на глобальный ВВП хорошо прослеживается до 2008 г., после чего вклад экспорта в мировой ВВП начал снижаться, и так будет продолжаться в краткосрочной перспективе. Вклад глобального экспорта в глобальный ВВП оценен по показателю добавленной стоимости национального происхождения в экспорте, по данным WIOD. Второй фактор изменения ВВП, не связанный с изменением экспорта, есть вклад внутреннего спроса в ВВП. Таким образом, с 2008 г. рост мировой экономики все в большей степени опирается на рост внутреннего спроса (рис. 4).

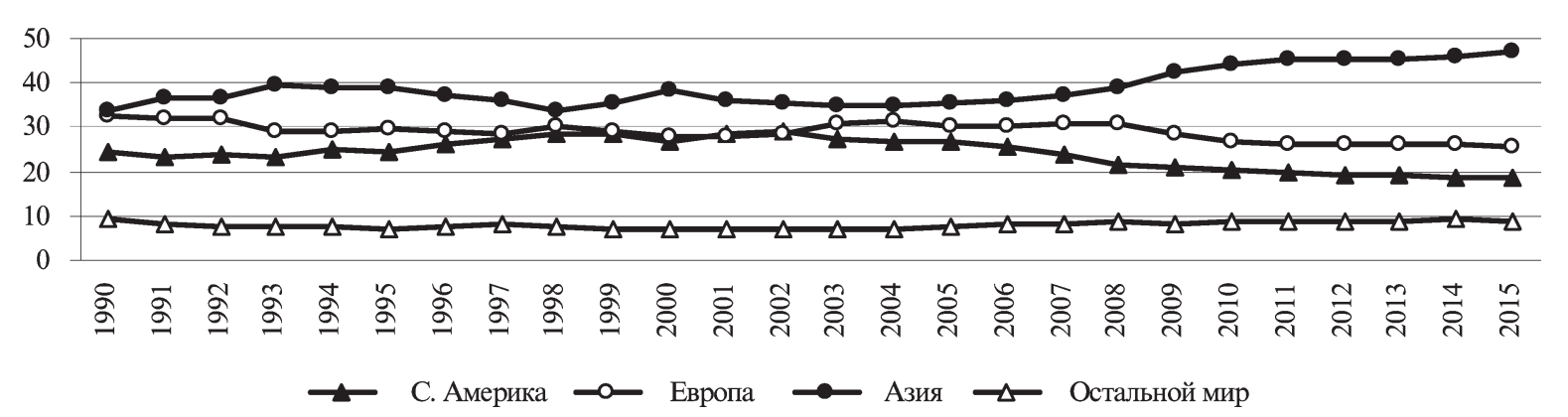

Рис. 3. Доля регионов в общем объеме выпуска продукции наукоемкой промышленности, \%

Источник. Рассчитано по данным Eora.

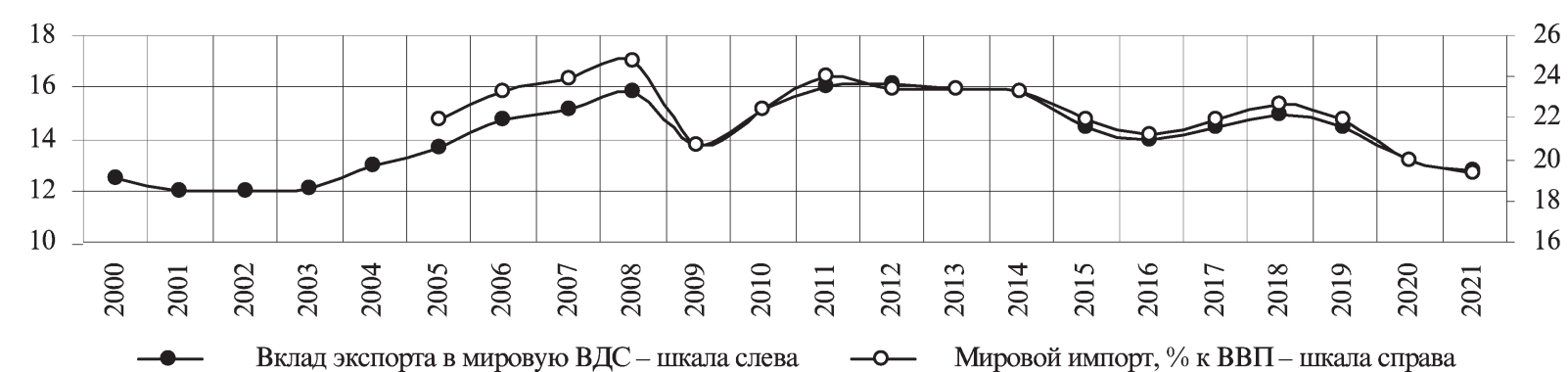

Рис. 4. Вклад глобального экспорта (в глобальный ВВП) и мировой импорт - анализ и прогноз, \%

Источник. Построено с 2000 по 2014 г. по данным WIOD; далее - на основе корреляционной связи с глобальным импортом. Глобальный импорт до 2019 г.: URL: https://stats.oecd.org/\#. Прогноз глобального импорта на 2020 г. 9\%, на 2021 г. - 3\% к предыдущему году. 
Анализ цепочек стоимости на основе региона происхождения промежуточных продуктов. Для каждой экономики мира была рассчитана пропорция, описанная формулой (2) - вклад национального (НЦС), внутрирегионального (РЦС) и глобального (ГЦС) промежуточного потребления в общем объеме промежуточных затрат. Анализ проводился как для экономик в целом, так и для выбранных наукоемких отраслей промышленности. Структура промежуточного потребления характеризует преобладание в анализируемой экономике цепочек стоимости соответствующего уровня иерархии - национальных, региональных или глобальных (рис. 5).

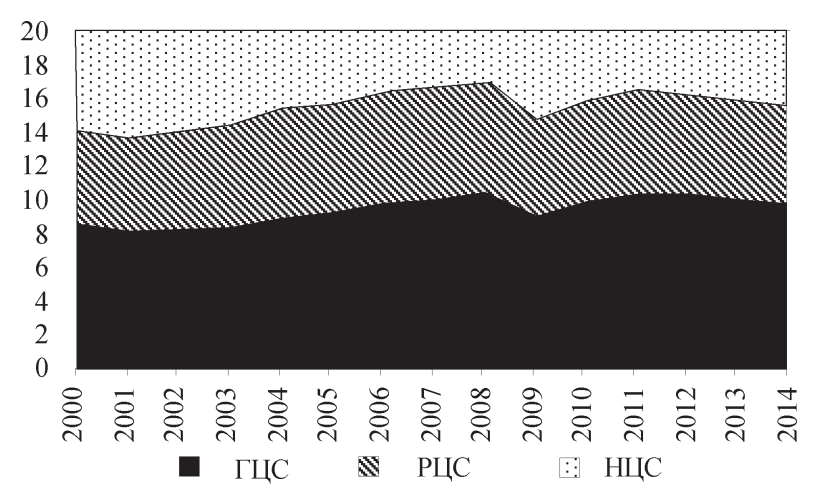

Рис. 5. Доля национальных, региональных и глобальных цепочек стоимости в промежуточном потреблении мировой экономики, \%

Источник. Рассчитано по данным WIOD.
Анализ показал, что в промежуточном потреблении мировой экономики в целом доля НЦС составляет в среднем 85\%, РЦС 6 и ГЦС $-9 \%$, и эта пропорция с течением времени мало меняется. По наукоемким промышленным продуктам доля НЦС составляет $78 \%$, РЦС - 9 и ГЦС - 13\%, пик роста ГЦС и РЦС пришелся на 2007 г., затем доля национальной составляющей промежуточного потребления снова выросла. Нужно отметить тесную связь суммы регионального и глобального промежуточного потребления, в процентах к его общему объему (рис. 5), с показателем вклада глобального экспорта в мировой ВВП (рис. 4). Данные показатели, равные в среднем 15\%, и есть характеристика «глубины проникновения» ГЦС в национальные экономики, и если до 2008 г. она увеличивалась, то потом начала снижаться. Некоторые детализированные результаты анализа представлены на рис. 6 .

Как видно, во всех регионах мира наибольшая доля промежуточных затрат относится к национальному уровню. В азиатских экономиках доля национального промежуточного потребления не меняется и составляет 85\% для наукоемких промышленных продуктов, для других продуктов остается еще выше. Национальная составляющая промежуточных затрат в наукоемкой промышленности Северной Америки сократилась с 82 до 77\%, и главным образом за счет увеличения глобальной состав-

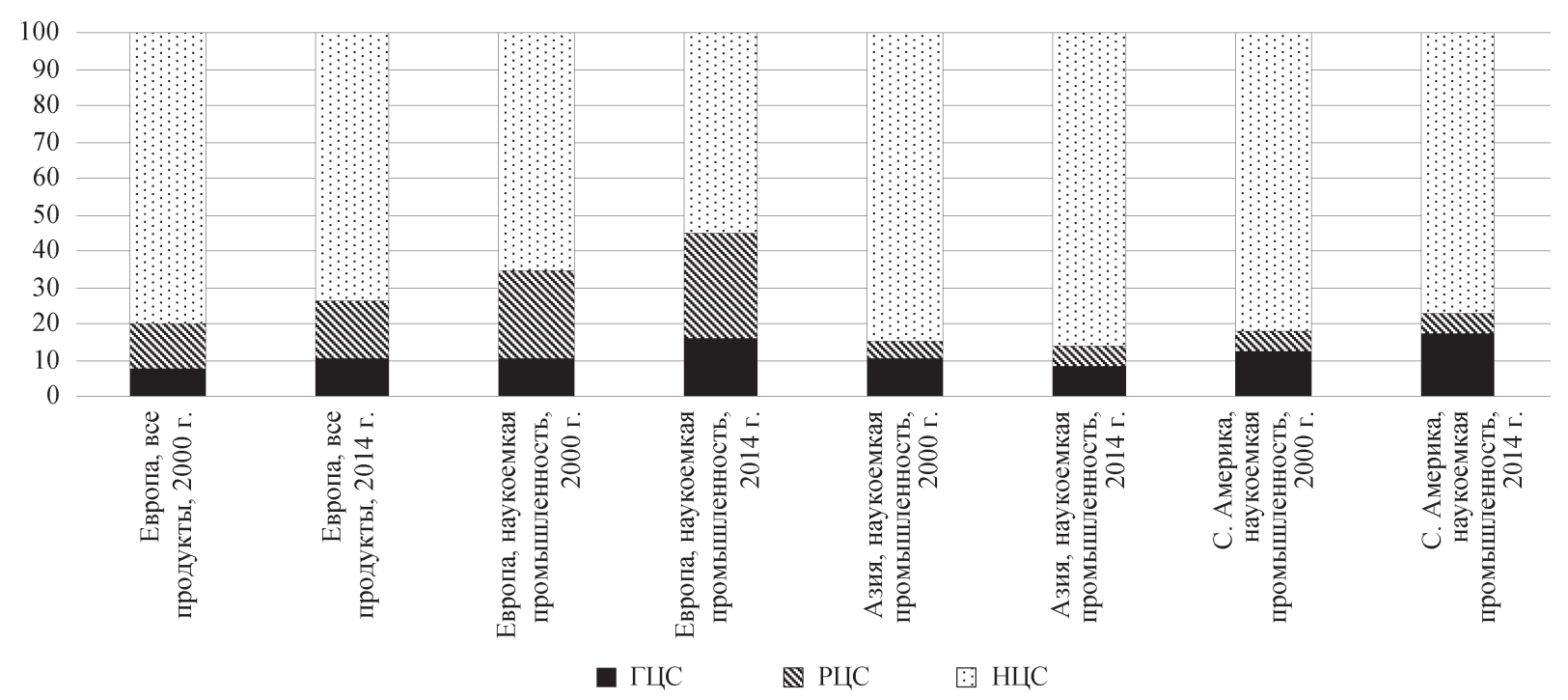

Рис. 6. Структура промежуточного потребления крупнейших экономических регионов мира, \% Источник. Рассчитано по данным WIOD. 
ляющей - продуктов из-за пределов региона. Наибольший уровень интеграции в РЦС и ГЦС демонстрируют европейские производители наукоемких товаров: региональная составляющая промежуточных затрат выросла с 23 до 28\%, национальная - сократилась с 66 до $55 \%$.

Представление о развитии процесса промышленной кооперации зависит от точки мира, из которой за ним наблюдают. Если смотреть из Северной Америки, то наиболее заметен тренд увеличения глобальной части производственных затрат. Взгляд из Европы позволяет представить глобализацию через регионализацию, когда региональная промышленная кооперация растет наибольшими темпами. В Азии структура себестоимости продукции мало меняется с течением времени, подавляющая часть промежуточных продуктов создается отечественными предприятиями.

Если национальные цепочки стоимости доминируют во всех регионах мира, то интересно сравнить, какая из национальных цепочек больше, например, в отраслях наукоемкой промышленности. На рис. 7 показаны доли промежуточного потребления крупнейших экономик в общемировом промежуточном потреблении в отраслях наукоемкой промышленности.

Китайская экономика часто воспринимается как «мировой сборочный цех», который осуществляет лишь сборку готовой продукции из импортных деталей, однако данные рис. 7 этот вывод опровергают. Ки-

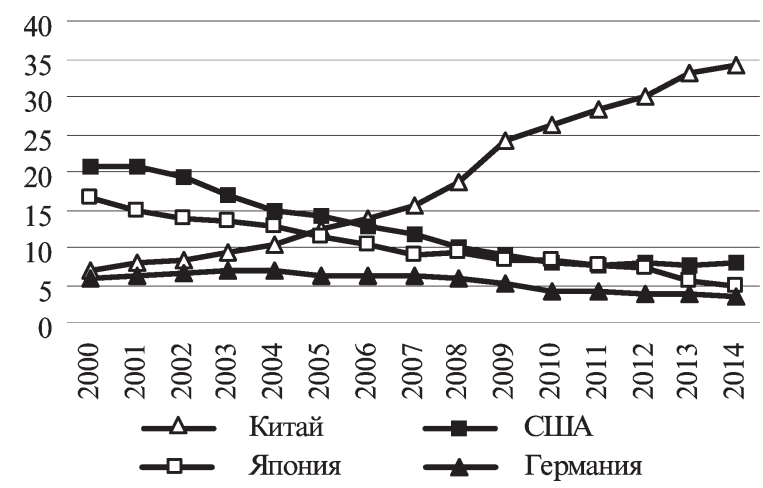

Рис. 7. Динамика доли национального промежуточного потребления в общемировом промежуточном потреблении для отраслей наукоемкой промышленности крупнейших экономик, \%

Источник. Рассчитано по данным WIOD. тайская сборка продуктов Apple из производимых другими странами компонентов, о которой говорилось выше, является исключением из правила и не подтверждается отраслевой статистикой. Китай действительно стал крупнейшим мировым производителем полного цикла, выпускающим наибольшую в мире долю частей и компонентов сложной технической продукции. Этих промежуточных продуктов Китай производит вдвое больше, чем США, Япония и Германия вместе взятые.

Структура промежуточного потребления и экономическая безопасность. Пропорция между национальной, региональной и глобальной составляющими общего промежуточного потребления зависит от размера экономики: чем он меньше, тем меньше национальная составляющая промежуточных затрат. Но больше ли глобальная? Хрупкость ГЦС заведомо несет малым экономикам риски, ставит их в зависимость от геополитической ситуации в регионе. Способом снижения рисков становится объединение малых стран в экономический союз с организацией производства необходимых товаров и услуг внутри союза на основе внутрирегиональной производственной кооперации. Таким образом поступили страны - члены Европейского союза, в результате доля глобальной (внерегиональной) части промежуточных затрат малых экономик ЕС невелика (табл. 3).

Крупные экономики, такие как США и Китай, и без экономических союзов в значительной степени самообеспечены производственными ресурсами. Даже в Турции национальная составляющая промежуточного потребления находится на высоком уровне, но в России этот показатель ниже.

Уязвимость России обусловлена не столько преобладанием минеральных продуктов в экспорте, сколько отсутствием отечественного производства необходимых для удовлетворения внутреннего спроса продуктов и их компонентов. Если бы Россия могла производить сама все остальные продукты, приобретаемые за счет экспортных поступлений, проблем бы не было. Значительная часть производственных процессов в России использует импортные компоненты, замещение которых отечественными 


\begin{tabular}{|l|c|}
\hline \multicolumn{3}{|c|}{$\begin{array}{c}\text { Таблица } 3 \\
\text { национального и регионального }\end{array}$} \\
промежуточного потребления по некоторым \\
странам
\end{tabular}

Источник. Рассчитано по данным WIOD за 2014 г., для Беларуси - по данным Системы таблиц «Затраты Выпуск» за 2018 г., а также Платежного баланса.

требует времени, инвестиций и технологий. Региональная интеграция в рамках ЕАЭС нужна России не в меньшей степени, чем остальным странам - участникам ЕАЭС, включая Беларусь. Экономики Беларуси и России уязвимы перед возможностью разрыва глобальных цепей поставок, поэтому углубление производственной кооперации необходимо обеим странам.

\section{Глубину экономической интеграции} стран и регионов мира лучше измерять не объемом экспорта и импорта, а показателями страны происхождения промежуточных продуктов, используемых при выпуске собственных товаров и услуг. Данный подход позволяет определять интенсивность производственной кооперации между отечественными и зарубежными фирмами и характеризует степень участия каждой экономики в глобальных, региональных и национальных цепочках стоимости.

Углубление региональной экономической интеграции представляется закономер-

ным процессом в условиях усиления факторов глобальной нестабильности. Открытая экономика вне экономических союзов становится крайне уязвимой. Интеграция Беларуси в экономический союз обусловлена объективными экономическими закономерностями. Эти закономерности уже привели к экономической интеграции в рамках Европейского союза. Вопрос о преимуществах экономической интеграции именно в ЕАЭС выходит за рамки данной работы.

Региональная интеграция сама по себе не решает проблем экономической безопасности, в дополнение к ней нужно расширять рынок ЕАЭС на основе производственной кооперации в выпуске необходимых для удовлетворения спроса товаров и услуг. Решение данной задачи обеспечивает устойчивость экономик к внешним шокам.

MRIO Eora и WIOD пока что не пригодны для анализа экономик ЕАЭС ввиду высокой погрешности данных. Нужно совершенствовать данную методологию, включая в межрегиональные таблицы экономики ЕАЭС. Кроме того, для уточнения полученных результатов следует разработать модель разделения промежуточного потребления по регионам на основе полных затрат импорта в конечном использовании товаров и услуг, а не прямых затрат импорта в валовом выпуске. Это позволит исключить повторный счет отечественных и импортных промежуточных продуктов при определении региона их происхождения.

\section{СПИСОК ЛИТЕРАТУРЫ (REFERENCES)}

Быков А.А., Седун А.М. 2015. Перспективы пост- и неоиндустриального развития в условиях возможной трансформации системы международного разделения труда. Белорусский экономический журнал. № 2. С. 4-23. [Bykau A.A., Sedun A.M. 2015. Prospects for post- and neoindustrial development in conditions of a possible transformation of the international division of labor system. Belorusskiy ekonomicheskiy zhurnal. No 2. PP. 4-23. (In Russ.)]

Волгина Н.A. 2020. Изучение глобальных цепочек стоимости: роль международных организаций. Вестник международных организащий. Т. 15. № 2. C. $255-285$. DOI: $10.17323 / 1996-7845-2020-$ 
02-12 [Volgina N.A. 2020. Global value chain research: The role of international organisations. Vestnik mezhdunarodnykh organizatsiy. Vol. 15. No 2. PP. 255-285. (In Russ.)]

Лагутина М.Л., Михайленко Е.Б. 2020. Регионализм в глобальную эпоху: обзор зарубежных и российских подходов. Вестник Российского университета дружбы народов. Серия: международные отношения. Т. 20. № 2. С. 261-278. [Lagutina M.L., Mikhaylenko E.B. 2020. Regionalism in global era: Overview of foreign and Russian approaches. Vestnik Rossiyskogo universiteta druzhby narodov. Seriya: mezhdunarodnye otnosheniya. Vol. 20. No 2. PP. 261-278. (In Russ.)]

Пархименко В.А. 2020. Анализ мировой ИТ-индустрии на базе таблиц «Затраты-Выпуск» средствами языка R. Big Data и анализ высокого уровня: сборник материалов VI международной научно-практической конференции. С. 376-386. [Parkhimenka U.A. 2020. Analysis of the global IT industry based on input-output tables using R. Big Data $i$ analiz vysokogo urovnya: sbornik materialov VI mezhdunarodnoy nauchno-prakticheskoy konferentsii. PP. 376-386. (In Russ.)]

Румянцев М.A. 2014. Экономика общества постмодерна: критический анализ. Ученые записки Санкт-Петербургского имени В.Б. Бобкова филиала Российской таможенной академии. № 3. C. 166-181. [Rumyantsev M.A. 2014. The economics of postmodern society: A critical analysis. Uchenye zapiski Sankt-Peterburgskogo imeni V.B. Bobkova filiala Rossiyskoy tamozhennoy akademii. No 3. PP. 166181. (In Russ.)]

Рязанов В.Т. 2012. Кризис глобализации и его системные последствия. Вопросы новой экономики. № 3. C. 4-10. [Ryazanov V.T. 2012. Crisis of globalization and its system consequences. Voprosy novoy ekonomiki. No 3. PP. 4-10. (In Russ.)]

Янчук А.Л. 2007. Анализ внешнеторговых связей Республики Беларусь со странами СНГ с использованием гравитационной модели торговли. Труд. Профсоюзы. Общество. № 1. С. 68-73. [Yanchuk A.L. 2007. Analysis of foreign trade relations of the Republic of Belarus with the CIS countries using the gravity model of trade. Trud. Profsoyuzy. Obshchestvo. No 1. PP. 68-73. (In Russ.)]

Boys J., Andreoni A. 2020. Value chain directionality, upgrading, and industrial policy in the Tanzanian textile and apparel sectors. WIDER Working Paper 2020/93. URL: https://doi.org/ 10.35188/UNU-WIDER/2020/850-4

Brun J-F, Carrure C., Guillaumont P., de Melo J. 2005. Has Distance Died? Evidence from a Panel Gravity Model. The World Bank Economic Review. Vol. 19. No 1. PP. 99-120.

Carrère C., de Melo J. 2009. Has distance died? An update. VoxEU E CEPR Coverage of the Covid-19 Global Pandemic. URL: https://voxeu.org/ article/distance-puzzle-resides-poor-economies

Keijser C., Belderbos R., Goedhuys M. 2021. Governance and learning in global, regional, and local value chains: The IT enabled services industry in South Africa. World Development 141. URL: https://doi.org/10.1016/j.worlddev.2021.105398

Lenzen M., Kanemoto K., Moran D., Geschke A. 2013. Building Eora: A Global Multi-regional InputOutput Database at High Country and Sector Resolution. Economic Systems Research. Vol. 25. Iss. 1. PP. 20-49. DOI: 10.1080/09535314.2013.769938

Lenzen M., Kanemoto K., Moran D., Geschke A. 2012. Mapping the structure of the world economy. Environmental Science \& Technology. Vol. 46. No 15. PP. 8374-8381.

Leontief W. 1977. The future of the world economy. Socio-Economic Planning Sciences. Vol. 11. No 3. PP. 171-182.

Leontief W., Strout A. 1963. Multiregional input-output analysis. Structural interdependence and economic development. London: Macmillan. PP. 119150.

Lund S., Manyika J., Woetzel J., Bughin J., Krishnan M., Seong J., Muir M. 2019. Globalization in transition: The future of trade and value chains. McKinsey Global Institute. 144 p.

Schwab K., Malleret Th. 2020. COVID-19: The Great Reset. Geneva: Forum Publishing. 212 p.

Timmer M.P., Los B., Stehrer R., de Vries G.J. 2016. An Anatomy of the Global Trade Slowdown based on the WIOD 2016 Release. GGDC Research Memorandum 162. 65 p.

Timmer M.P., Dietzenbacher E., Los B., Stehrer R., de Vries G.J. 2015. An Illustrated User Guide to the World Input-Output Database: the Case of Global Automotive Production. Review of International Economics. Vol. 23. No 3. PP. 575605. DOI:10.1111/roie. 12178 
In citation: Belorusskiy Ekonomicheskiy zhurnal. 2021. No 1. PP. 45-58.

Belarusian Economic Journal. 2021. No 1. PP. 45-58.

\title{
HIERARCHY OF VALUE CHAINS: STATISTICAL ANALYSIS BASED ON WIOD AND EORA DATA
}

\author{
Aliaksei Bykau ${ }^{1}$, Uladzimir Parkhimenka ${ }^{2}$, Andrei Sedun ${ }^{1}$ \\ Author affiliation: ${ }^{1}$ Belarussian State Economic University (Minsk, Belarus); \\ ${ }^{2}$ Belarusian State University of Informatics and Radioelectronics (Minsk, Belarus). \\ Corresponding author: Aliaksei Bykau (aliaksei.bykau@yandex.ru).
}

ABSTRACT. The article presents analysis of long term trends and patterns typical of processes in international production networks within the framework of global value chains. It aims at identifying perspectives for Belarusian economy in global and regional labor division system and creating strategic recommendations. Research methodology is based on statistical «input - output» analysis and other methods of quantitative data analysis using the $\mathrm{R}$ language. The research information base is formed by analytical reports of international organizations and consulting companies, as well as data from interregional tables WIOD and Eora.

KEYWORDS: multi-regional input-output tables, national, regional and global value chains, macroeconomic indicators, Eora, WIOD.

JEL-code: C10, C67, D57, F63, O10.

DOI: $10.46782 / 1818-4510-2021-1-45-58$

Received 23.02.2021 